\title{
Research on the Application of Li Nationality Costume Pattern in the Cultural and Creative Clothing Product Design of Wenzhou She Nationality Tourism Area
} Yuxue Zou

Haikou College of Economics, Haikou 571127, Hainan, China.

Abstract: "Distinctive costume patterns of Li nationality" is the precipitation of history, the accumulation of culture, and the crystallization of diligence and wisdom of people Li nationality. In Wenzhou She nationality tourist area, the design of cultural and creative clothing products badly needs such history, culture and wisdom. This paper focuses on "the analysis of the distinctive costume patterns of Li nationality" and "the application of the distinctive costume patterns of Li nationality in the cultural and creative clothing product design of Wenzhou She nationality tourism area". It is hoped that the ingenious application of the "distinctive custom patterns of Li nationality" will bring new inspiration and ideas to the design of cultural and creative clothing products in Wenzhou She tourism area.

Keywords: Li Nationality Clothing; Distinctive Pattern; She Nationality Tourism Area; Clothing Product Design

The design of "cultural and creative products" carries strong nationality, culture and innovation, which puts forward higher requirements for designers. "Distinctive costume patterns of Li nationality" is the embodiment of Li nationality people's diligence and wisdom from generation to generation and conveys the profound culture of the nationality. For the designers of modern cultural and creative products, distinctive costume patterns of Li nationality are rich for materials and the source of inspiration. The purpose of this paper is to explore the application of distinctive costume patterns of Li nationality in the design of cultural and creative clothing products in Wenzhou She nationality tourism area, in order to better promote the Li culture and meet the aesthetic needs of people for cultural and creative clothing products in the new era.

\section{Analysis of the distinctive costume pattern of Li nationality}

\subsection{On the expression form of distinctive costume pattern of Li nationality}

On the "form of expression", the distinctive costume pattern of Li nationality can be divided into two types according to its presented characteristics: concrete and abstract. To be specific, on the one hand, there are many forms of "concrete" in the distinctive costumes pattern of Li nationality, which mainly use points, lines and surfaces as elements to outline some figures. Most of them are irregular geometric figures based on the real objects in life, such as pots, bowls, ladles, basins, etc. This kind of concrete manifestation plays the role of "recording", and truly reflect the daily life of Li nationality people, with high research value; On the other hand, there are many forms of "abstract" in the distinctive costume pattern of Li nationality, such as diamond, rectangle, triangle and so on ${ }^{[1]}$, or combining and overlying of those figures. The inspiration of the creation is the life and culture of the Li nationality people, and they hope to reflect their folk customs through the characteristics and combination of these figures. Most of the abstract forms of expression are related to nature to reflect the attitude towards nature of Li nationality.

Copyright $(2020$ Yuxue Zou

doi: 10.18686/ahe.v4i10.2918

This is an open-access article distributed under the terms of the Creative Commons Attribution Non-Commercial License (http://creativecommons. org/licenses/by-nc/4.0/), which permits unrestricted non-commercial use, distribution, and reproduction in any medium, provided the original work is properly cited. 


\subsection{The overall composition of the distinctive costume pattern of Li nationality}

From the perspective of integrity, costume pattern of Li nationality also has its own characteristics, which can be divided into "main pattern" and "sub pattern". Specifically speaking, first, in the Li nationality clothing, the more common "main pattern" includes Hercules, human figure and so on. The corresponding "sub patterns" are generally animals or plants, such as dragon patterns, divine tree patterns etc. Second, in Li nationality's clothing, the layout of "main pattern" and "sub pattern" carrier some certain fastidious are symmetrical giving a full and neat feeling. The difference between the main pattern and sub pattern can be clearly distinguished at a glance. This overall composition reflects the values of the traditional Li nationality people, and they believe that man is the master of everything. The human figure pattern is used as the main pattern, while the natural scenery is dominated by human ${ }^{[2]}$, which is often used as sub pattern. In addition, in the overall composition, the Li nationality people optimize the overall composition through the compound pattern of two continuous and scattered patterns in order to highlight the aesthetics. These small details on the composition well reflect the aesthetic value of the distinctive costume pattern of Li nationality.

\subsection{Color application on distinctive costume pattern of Li nationality}

The expression of patterns is inseparable from the ingenious use of colors. The color application on distinctive costume pattern of Li nationality also shows its connotation. To be specific, on the one hand, the warp lines of the patterns are usually dark blue or black while the weft lines are mainly white, red, purple, etc. Through the interweaving of these colors, a more powerful visual effect is formed, which makes the distinctive costume pattern of Li nationality more appreciative; on the other hand, the traditional people of Li nationality attaches great importance to the coloring method for color, mainly using "plant dyeing technology". This coloring method shows the feeling of ancient color ${ }^{[3]}$, adding a simple temperament under the bright color, and highlight the characteristics of nationality and culture to the costume of Li nationality.

\section{Research on the application of $\mathrm{Li}$ nationality costume pattern in the cultural and creative clothing product design of Wenzhou She nationality tourism area}

\subsection{Combining with expression form of distinctive costume pattern of Li nationality}

Combined with the expression form of distinctive costume pattern of Li nationality, these practices can be carried out in the cultural and creative clothing product design of Wenzhou She nationality tourism area. On the one hand, in the cultural and creative clothing product design, the "concrete" irregular geometric figure is used to show the real life of She nationality people, such as cups for drinking, bowls for eating, handicrafts, etc. In this way, ordinary costume has national and cultural characteristics, which can attract more tourists' attention. On the other hand, in the design of cultural and creative clothing products, "abstract" is applied, such as diamond, rectangle, triangle, etc. to enrich the clothing design. Moreover, combined with the local costume of She nationality, these figures are also expressed by a variety of combination relations, which express their love for life and attitude towards nature ${ }^{[4]}$. This kind of abstract design concept endows more imagination to the costumes. When tourists purchase, they also explore the culture She nationality with great interest, which is conducive to the spread of She culture.

\subsection{Referring to the overall composition of the distinctive costume pattern of Li nationality}

Reference to the overall composition of distinctive costume pattern of Li nationality brings a lot of innovative ideas to designers. Specifically, first, the overall composition form of "main pattern" and "sub pattern" is in the design of cultural and creative clothing products in order to better show the characteristics of She nationality. Important and representative things are selected as the main pattern according to the value orientation of the She nationality people, while other things are selected as the sub pattern according to the interests of She nationality people. This kind of composition form of mutual cooperation can better enrich the sense of layers of clothing and make the nationality characteristics of clothing more prominent; Second, in the design of cultural and creative clothing products, the value point of tourist clothing that purchased by tourists is often reflected in the connotation of clothing ${ }^{[5]}$. The transmission of the connotation can be reflected by the relationship between "main pattern" and "sub pattern". For example, She nationality people have a great respect for nature. Flowers and plants, sun and moon, mountains and rivers are used as the main composition to convey the belief of people of She nationality to tourists. 


\subsection{Color application with the distinctive costume pattern of Li nationality}

From the perspective of color application, with the help of the color application in the distinctive costume pattern of $\mathrm{Li}$ nationality, we can better innovate the cultural and creative clothing product design of Wenzhou she tourism area. Specifically speaking, on the one hand, in the design of cultural and creative clothing products, with the color application of the distinctive costume pattern of Li nationality, the "single" clothing coloring style can be changed, instead by a new form of color effect that interweaved by the warp and weft of different colors. Red, representing auspiciousness and white, representing purity, are favorite colors of She nationality people. Designers design characteristic clothing for She nationality by the interweaving of these two colors, so as to embody the aesthetic tendency of She nationality people, and increase the nationality details of costumes; on the other hand, in the design of cultural and creative clothing products, referring to the color method of the distinctive costume pattern of Li nationality, "plant dyeing technology" is adopted by designers on characteristic clothing for She nationality ${ }^{[6]}$. In this way, the simple temperament brought by plant dyeing technology is enjoyed by tourists, and the nationality characteristics and commemorative significance of She nationality clothing are better recognized.

\section{Conclusion}

From the view of "cultural and creative clothing product design", the distinctive costume pattern of Li nationality enriches the design concept and design form and promotes the development of cultural and creative clothing product design in China. However, from the perspective of "cultural heritage", it is precisely because of the ingenuity of the designers that the distinctive costume pattern of Li nationality can be renewed with brilliance, which is loved by more and more people, so that the Chinese national culture is inherited and carried forward. It can be seen that the application of Li nationality costume pattern in the cultural and creative clothing product design of Wenzhou She nationality tourism area will achieve mutual promotion and success.

\section{References}

1. Zhang Y. The significance and ideas of museum cultural and creative products development. Time Economy and Trade 2017; (33): 36-37.

2. Zheng Y. Application of local historical and cultural elements in cultural and creative products —— Taking Jiujiang Museum as an example. Peony 2018; (11): 51-52.

3. Wang D. Design of cultural and creative products based on emotional experience - Taking Hangzhou Museum as an example. Packaging World 2018; (1): 25-27.

4. Jiang L. Application of traditional elements in cultural and creative product design. Industrial Design 2017; (12): 127.

5. Lin K. An analysis of Li Nationality's Dress with its cultural connotation and value. Fashion Guide 2017; (2): 24-31.

6. Ju F, Chen Y. Traditional embroidery pattern art of Li Nationality in China. Nanjing: Southeast University Press 2017; (7): 32-33. 